удк 336.6

\author{
С. А. Будько \\ Байкальский государственный университет, \\ г. Иркутск, Российская Федерация
}

\title{
ФОРМАЛЬНЫЕ УСЛОВИЯ СБАЛАНСИРОВАННОСТИ РАСПРЕДЕЛИТЕЛЬНОЙ ПЕНСИОННОЙ СИСТЕМЫ
}

\begin{abstract}
АНнОТАЦия. В настоящее время многочисленные и зачастую взаимосвязанные проблемы несбалансированности пенсионных систем распределительного типа обостряются вследствие стагнации экономик и ограниченных возможностях дотирования по причине сокращения бюджетных доходов. Современные исследования свидетельствуют о необходимости изменений параметров пенсионной системы, а также воздействия на связанные внешние факторы для повышения уровня обеспеченности выплат поступающими взносами. В статье анализируется влияние макроэкономических и демографических факторов на устойчивость распределительной пенсионной системы, а также формулируются условия обеспеченности выплат, реализация которых в силу макроэкономических, политических и социальных аспектов не всегда допустима. Выявленные обстоятельства свидетельствуют о несостоятельности распределительного метода бездотационного обеспечения пенсионной защиты на уровне современных социальных стандартов и актуализируют поиск альтернативных способов организации финансов пенсионной системы.

КЛЮЧЕВЫЕ СЛОВА. Реформирование; пенсионная система; распределительная пенсионная схема; демография; страховой взнос; сбалансированность.

ИНФОРМАЦИЯ О СТАТЬЕ. Дата поступления 8 февраля 2016 г.; дата принятия к печати 26 февраля 2016 г.; дата онлайн-размещения 23 марта 2016 г.

ФИНАНСИРОВАНИЕ. Государственного задания № 26.1348.2014/К на выполнение научно-исследовательских работ в сфере научной деятельности в рамках проектной части. Проект №1348 «Влияние теневого сектора экономики на качество жизни населения в России и Укра-ине: сравнительный ана-лиз». (Номер госрегистрации в ФГАНУ ЦИТиС 114091140015).
\end{abstract}

\section{S. A. Budko \\ Baikal State University, Irkutsk, Russian Federation}

\section{FORMAL CONDITIONS FOR EQUATION OF THE UNFUNDED PENSION SCHEME}

\begin{abstract}
At the present time, numerous and frequently interrelated problems of imbalance of the unfunded pension scheme are becoming even more serious due to stagnation of economies and limited possibilities for subsidies on account of reduction of budget revenues. Current research studies testify the necessity of changing the pension scheme parameters, as well as the impact on the interrelated external factors to improve the level of sufficiency of payments by received contributions. The article analyzes the impact of macroeconomic and demographic factors on sustainability of the unfunded pension scheme, as well as formulates the conditions of payment supportability, which implementation due to macroeconomic, political and social aspects is not always made available. The circumstances identified testify the inconsistency of the unfunded method for unsubsidized provision of pension protection at the levels of modern social standards and make topical the search of alternative ways of arranging the pension scheme finance. KEYWORDS. Reforming; pension scheme; unfunded pension scheme; demography; insurance fee; equation.
\end{abstract}

ARTICLE INFO. Received February 8, 2016; accepted February 26, 2016; available online March 23, 2016.

\section{Baikal Research Journal}


FINANCING. The state task № 26.1348.2014/for implementation of scien-tific-research works in the field of scientific activities within the project. Project № 1348 »Influence of shadow econo-my on the quality of life of the population in Russia and Ukraine: compar-ative analysis» (Number of state registra-tion in RUSSIAN Tsitis 114091140015).

Актуальность исследования условий устойчивости распределительной схемы формирования определенного уровня пенсионной защиты обусловливается требованием положений современных международных социальных стандартов обеспечения минимальных норм компенсации заработной платы периодической выплатой в случае утраты трудоспособности, а также подготовкой Правительством РФ ратификации 102-й Конвенции Международной организации труда в условиях снижения уровня компенсации дохода и углубляющейся несбалансированности бюджета Пенсионного фонда России (ПФР).

Вопросы формирования и использования финансовых ресурсов в рамках различных конструктивных моделей пенсионных систем исследованы в работах отечественных авторов достаточно полно [1-7], более того, значительную долю отечественных научных и общественных исследований на протяжении последних 20 лет занимают практические проблемы и негативные процессы в пенсионной сфере [8-16], которые Правительством РФ рассматриваются основным вызовом долгосрочного социально-экономического развития страны ${ }^{1}$. В ряде работ производится оценка результатов проведенных ранее реформ национальных пенсионных систем с учетом последствий мирового финансового кризиса [17-18] и формулируются адекватные способы адаптации ${ }^{2}$ к новым демографическим условиям [19]. Соответственно, пенсионная система представляется конструктивным единством методов (распределительного, накопительного), уровней (государственного, корпоративного, индивидуального), моделей (континентальной, англосаксонской, советской) и принципов (профессионально-трудовой солидарности, социальной солидарности, государственного патернализма).

В условиях довления распределительного пенсионного страхования над другими формами компенсации утраченного дохода обеспечение пенсионной защиты в России сопряжено с проблемами снижения уровня компенсации пенсией заработка, углубляющейся несбалансированностью бюджета ПФР, высоким уровнем стабилизационных трансфертов из федерального бюджета. Более того, среди мировых тенденций в области реформирования национальных пенсионных систем, содержащих оценку результатов проведенных ранее преобразований и уроков мирового финансового кризиса, следует отметить ориентацию на поддержание доходов всех социальных групп, объективную необходимость адаптации пенсионных систем к социально-демографическим изменениям, политическую осторожность в вопросе увеличения пенсионного возраста по причине сопротивления со стороны определенных возрастных когорт избирателей, фокусирование политических решений в рамках решения текущей сбалансированности пенсионной системы в ущерб долгосрочному развитию.

Среди внешних причин обозначенных проблем экономисты выделяют структуру занятости, показатели производительности труда, инфляцию, большой объем теневой занятости и скрытой заработной платы, низкую мотивацию к уплате взносов,

${ }^{1}$ Об утверждении Стратегии долгосрочного развития пенсионной системы Российской Федерации : распоряжение Правительства РФ от 25 дек. 2012 г. № 2524-р / Собрание законодательства Российской Федерации. 2012. № 53 (ч. 2). Ст. 8029.

${ }^{2}$ An Agenda for Adequate, Safe and Sustainable Pensions [Electronic resource] : WHITE PAPER / European Commission. 2012. URL : http://www.cicero-group.com/wp-content/uploads/2012/02/Pensions-White-Paper-Special1.pdf.

\section{Baikal Research Journal}

электронный научный журнал Байкальского государственного университета 
изменение коэффициента демографической поддержки. Внутренними негативными факторами являются несбалансированность параметров пенсионной системы. В этой связи установление формальных условий обеспеченности распределительной пенсионной системы позволит сформулировать предпосылки развития системы обязательного пенсионного страхования с учетом современных социальных стандартов.

В рамках распределительного метода финансирование выплат пенсий по старости осуществляется за счет уплаченных участниками в этом же периоде взносов, а устойчивость системы в виде математической конструкции представляется следующей формулой

$$
S b_{N}+(S u)=S w_{N}+(T),
$$

где $S b_{N}$ - объем пенсионных выплат в периоде $N ; S u$ - превышение поступлений над выплатами; $S w_{N}$ - объем взносов в периоде $N$; $T$ - превышение выплат над поступлениями.

Сумма выплат пенсий по старости в периоде определяется по формуле

$$
S b_{N}=\sum_{j=N-t-m}^{N-t} \sum_{i=0}^{W_{j}}\left(\overline{\sum_{k=N-t-m}^{N} P R_{i, k} I_{k, N}} A\right),
$$

где $j$ - года рождения плательщиков с $N-t-m$ до $N-t ; t$ - общеустановленный возраст назначения пенсии по старости; $m-$ количество лет от $t$ до $100 ; W_{j}-$ участники $j$ года рождения; $i$ - плательщик $j$ года рождения; $P R_{i, k}$ - годовой фонд оплаты труда $i$ плательщика в году $k ; I_{k, N}$ - коэффициент индексации взносов $k$-го года в году $N$;

$$
\sum_{k=N-t-m}^{N} \overline{P R_{i, k} I_{k, N}} A-
$$

сумма выплат пенсии по старости участнику в периоде $N$;

$$
\sum_{i=0}^{W_{j}}\left(\overline{\sum_{k=N-t-m}^{N} P R_{i, k} I_{k, N}} A\right)-
$$

сумма выплат пенсии по старости участникам $j$ года рождения в периоде $N$.

В момент времени $N$ участники осуществляют взносы в сумме, определяемой по формуле

$$
S w_{N}=\sum_{j=N-t}^{N} \sum_{i=0}^{W_{j}} P R_{i, k} R s t_{j},
$$

где $\sum_{i=0}^{W_{j}} P R_{i, k} R s t_{j}-$ сумма взносов участников $j$ года рождения; $W_{j}$ - участники, уплачивающие взносы в году $N ; P R_{i, N}$ - годовой фонд оплаты труда $i$ застрахованного лица в рассматриваемом году $N$; $R s t_{j}$ — тариф страхового взноса по распределительной составляющей для $i$ участника $j$ года рождения.

Тариф страхового взноса распределительной составляющей определяется исходя из социально приемлемого уровня компенсации дохода при социально обусловленном периоде взносов и выплат по формуле

$$
\text { Rst }_{j}=\frac{A \bar{m}}{\bar{n}},
$$

где $R s t_{j}$ - тариф взноса плательщика ј года рождения; $A$ - социально приемлемый уровень компенсации дохода; $\bar{m}-$ средний период осуществления выплат; $\bar{n}-$ средний период осуществления взносов.

В условиях сбалансированности распределительной составляющей величины $S u$ и $T$ в формуле 1 имеют нулевые значения, тогда подстановкой в данное выражение величин $S b_{N}$ из (2) и $S w_{N}$ из (3) с заменой $R s t_{j}$ на значение из (4) получим уравнение

\section{Baikal Research Journal}




$$
\sum_{j=N-t-m}^{N-t} \sum_{i=0}^{W_{j}}\left(\overline{\sum_{k=N-t-m}^{N} P R_{i, k} I_{k, N}}\right)=\sum_{j=N-t}^{N} \sum_{i=0}^{W_{j}} P R_{i, k} \frac{\bar{m}}{\bar{n}} .
$$

Таким образом, данная формула позволяет сформулировать условия обеспеченности ресурсами распределительной составляющей пенсионной системы в случае воздействия внешних факторов.

В условиях стабильной демографической структуры (постоянная величина коэффициента демографической нагрузки пенсионеров по старости) объем выплат должен соответствовать фонду оплаты труда, умноженному на отношение периода осуществления выплат к периоду осуществления взносов. Макроэкономические изменения, влекущие уменьшение фонда оплаты труда в экономике и суммы поступающих взносов, могут быть компенсированы увеличением тарифа взноса или уменьшением средней величины пенсионной выплаты, при этом размеры соответствующих изменений параметров могут быть выражены преобразованием формулы (5).

В условиях постоянного реального размера оплаты труда формула (5) примет следующий вид:

$$
\frac{\sum_{j=N-t-m}^{N-t} \sum_{i=0}^{W_{j}}}{\sum_{j=N-t}^{N} \sum_{i=0}^{W_{j}}}=\frac{\bar{m}}{\bar{n}} .
$$

Полученная формула характеризует демографический аспект устойчивости распределительного метода, т. е. коэффициент демографической поддержки пожилых должен соответствовать отношению среднего периода осуществления выплат к периоду осуществления взносов. Рост средней продолжительности жизни $\bar{m}$ может быть компенсирован увеличением среднего периода уплаты взносов $\bar{n}$, согласно правой части формулы (6). По причине роста численности пенсионеров

$$
\sum_{j=N-t}^{N-t} \sum_{i=0}^{W_{j}}
$$

при неизменном уровне тарифа для обеспечения условий формулы (6) увеличение объема выплат требует соответствующего изменения численности плательщиков

$$
\sum_{j=N-t}^{N} \sum_{i=0}^{W_{j}}
$$

Влияние макроэкономических и демографических показателей для поддержания обеспеченности распределительной системы собственными средствами может быть учтено изменением параметров, т. е. выполнением параметров формулы (5).

Анализ основных показателей исполнения бюджета ПФР по финансированию выплат трудовых пенсий по старости в 2014 г. (табл.) свидетельствует, что уровень сбалансированности составляет $76,3 \%$.

Согласно формуле (5) могут быть рассчитаны целевые значения макроэкономических и демографических показателей, которые позволят сбалансировать бюджет ПФР, связанный с выплатой рассматриваемого вида пенсий. При прочих равных условиях формально бюджет ПФР может быть сбалансирован при соответствующем изменении одного из следующих показателей ${ }^{3}$ :

${ }^{3}$ Сбалансированность может быть достигнута и при взаимосвязанном изменении показателей, которые в рамках целей настоящей статьи не рассчитывались.

\section{Baikal Research Journal}


- увеличение численности официально занятых в экономике до 59,4 млн чел. $(28,8 \%)$;

- рост среднемесячной заработной платы до 41846 р. (28,8 \% ) и фонда оплаты труда до 23164 млрд р. (28,8 \% );

- снижение коэффициента замещения пенсией утраченного заработка с 35,6 до 27,6 \% или среднего размера пенсии по старости до 8823 р. (23,7% );

- рост коэффициента демографической поддержки до 1,73;

- увеличение тарифа страхового взноса на весь фонд оплаты труда до 28,8 \% ;

- стимулирование граждан к более позднему установлению выплаты пенсии и сокращении численности получателей до 26,7 млн чел. (22,3%).

\section{Уровень сбалансированности бюджета Пенсионного фонда России по финансированию выплат трудовых пенсий по старости в 20142. и иелевые изменения значений показателей для его повышения}

\begin{tabular}{|c|c|c|c|c|}
\hline \multirow{2}{*}{$\begin{array}{c}\text { Факторы, влияющие на } \\
\text { устойчивость Пенсион- } \\
\text { ного фонда России }\end{array}$} & \multirow[t]{2}{*}{ Показатели } & \multicolumn{2}{|c|}{ Значения } & \multirow{2}{*}{$\begin{array}{l}\text { Целевые } \\
\text { измене- } \\
\text { ния, \% }\end{array}$} \\
\hline & & $\begin{array}{l}\text { факти- } \\
\text { ческие }\end{array}$ & целевые & \\
\hline \multirow{6}{*}{$\begin{array}{l}\text { Макроэкономика и демо- } \\
\text { графия }\end{array}$} & Численность занятых, млн чел. & 46,1 & 59,4 & 28,8 \\
\hline & Среднемесячная заработная плата, p. & 32495,0 & 41846,0 & 28,8 \\
\hline & Фонд оплаты труда, млрд р. & 17658,0 & 23164,0 & 31,2 \\
\hline & $\begin{array}{l}\text { Коэффициент замещения пенсией } \\
\text { заработка, \% }\end{array}$ & 35,6 & 27,6 & $-22,3$ \\
\hline & Средний размер пенсии по старости, р. & 11569,0 & 8823,0 & $-23,7$ \\
\hline & $\begin{array}{l}\text { Коэффициент демографической под- } \\
\text { держки }\end{array}$ & 1,34 & 1,73 & 28,8 \\
\hline \multirow[t]{3}{*}{ Доходная часть бюджета } & $\begin{array}{l}\text { Тариф страхового взноса (свыше пре- } \\
\text { дельной величины), \% }\end{array}$ & $\begin{array}{r}22,0 \\
(10,0)\end{array}$ & $\begin{array}{r}28,8 \\
(-)\end{array}$ & $\begin{array}{r}31,1 \\
(188,0)\end{array}$ \\
\hline & $\begin{array}{l}\text { Часть тарифа страхового взноса на фи- } \\
\text { нансирование пенсий по старости, \% }\end{array}$ & 20,6 & 27,1 & 31,2 \\
\hline & $\begin{array}{l}\text { Страховые взносы в Пенсионный фонд } \\
\text { России, млрд р. }\end{array}$ & 3885,0 & 5094,0 & 31,1 \\
\hline \multirow{2}{*}{$\begin{array}{l}\text { Расходная часть бюджета } \\
\text { по финансированию вы- } \\
\text { плат пенсий по старости }\end{array}$} & Численность получателей, млн чел. & 34,4 & 26,7 & $-22,3$ \\
\hline & Объем выплат, млрд р. & 4779,0 & 3644,0 & $-23,7$ \\
\hline \multirow{2}{*}{$\begin{array}{l}\text { Сбалансированность } \\
\text { бюджета по финансиро- } \\
\text { ванию выплат трудовых } \\
\text { пенсий }\end{array}$} & $\begin{array}{l}\text { Дефицит бюджета Пенсионного фонда } \\
\text { России, млрд р. }\end{array}$ & 1134,0 & 0,0 & - \\
\hline & $\begin{array}{l}\text { Обеспеченность собственными сред- } \\
\text { ствами, \% }\end{array}$ & 76,3 & 100,0 & 23,7 \\
\hline
\end{tabular}

* Страховые взносы в Пенсионный фонд России включают компенсацию выпадающих доходов в связи с установлением пониженных тарифов за счет средств федерального бюджета. Фонд оплаты труда не включает скрытую оплату труда и смешанные доходы.

Составлено по данным Пенсионного фонда России и Федеральной службы государственной статистики.

На стадии становления и развития пенсионных систем ведущая роль распределительного метода финансирования обусловливалась благоприятной макроэкономической и демографической ситуацией, заключающейся в росте численности плательщиков, реальной заработной платы, высоким коэффициентом демографической поддержки пенсионеров. Как отмечает Е. В. Агеева, старение население мира является результатом двух долгосрочных тенденций: снижения рождаемости и увеличения средней продолжительности жизни, что обусловливает второй «демографический переход», связанный с формированием новой модели равновесия

\section{Baikal Research Journal}


в возрастной структуре населения с увеличением разрыва между биологическим и «социально-экономическим» старением $[19$, с. 23$]$. При этом рост производительности труда и увеличение фонда оплаты труда в структуре валового внутреннего продукта не перекрывают негативное воздействие изменений, что приводит к необеспеченности распределительных пенсионных систем собственными ресурсами, необходимости внешних стабилизационных дотаций, возможности использования которых вследствие цикличности развития экономики и в условиях сокращения бюджетных доходов ограничены.

Таким образом, устойчивость пенсионных систем распределительного типа определяется соответствием внутренних параметров внешним условиям, которые динамично изменяются и заключаются во взаимосвязи социально-экономических и демографических факторов, включая экономическое развитие и рынок труда. Адаптация требует предупреждающих внутрисистемных изменений в части тарифа, ограничения возможностей раннего установления выплаты, которые в рамках рассматриваемой модели в силу макроэкономических, политических и социальных аспектов не всегда допустимы, что требует поиска альтернативных способов организации финансов и повышения уровня адаптивности пенсионной системы в целях бездотационного обеспечения пенсионной защиты на уровне современных социальных стандартов в долгосрочной перспективе.

\section{Список использованной литературы}

1. Борисенко Н. Ю. Построение национальной системы пенсионного обеспечения: теория и практика / Н. Ю. Борисенко // Финансы и кредит. - 2007. - № 17. - С. 54-65.

2. Дмитриев М. Э. Финансовое состояние и перспективы реформирования пенсионной системы в Российской Федерации / М. Э. Дмитриев // Пенсионная реформа в России: оценка специалистов / под ред. В. Н. Баскакова, А. С. Орлова. - М. : Пенсия, 1999. - С. 71-89.

3. Малева Т. М. Пенсионная реформа в России: история, результаты, перспективы : аналит. докл. / Т. М. Малева, О. В. Синявская. - М. : Поматур, 2005. - 76 с.

4. Ордин О. В. Моделирование процессов перехода к накопительной пенсионной системе : дис. ... канд. экон. наук : 08.00.13 / О. В. Ордин. - М., 2002. - 134 с.

5. Роик В. Д. Основы социального страхования: организация, экономика и право : учебник / В. Д. Роик. - М. : Изд-во Рос. акад. гос. службы, 2007. - 456 с.

6. Федотов Д. Ю. Основные этапы эволюции отечественной пенсионной системы / Д. Ю. Федотов // Историко-экономические исследования. — 2013. — Т. 14, № 3. - С. 70-97.

7. Kotlikoff L. J. The Coming Generation Storm: What You Need to Know about America's Economic Future / L. J. Kotlikoff, S. Burns. - London : The MIT Press, 2004. - 306 p.

8. Вовченко Н. Г. Направления развития системы пенсионного обеспечения в условиях структурной перестройки финансовой системы России / Н. Г. Вовченко, И. Н. Ефременко // Финансовые исследования. - 2009. - № 24. - С. 36-42.

9. Гонтмахер Е. Ш. Пути совершенствования российской пенсионной системы / Е. Ш. Гонтмахер // Уровень жизни населения регионов России. - 2008. - № 8. - С. 29-36.

10. Разработка пенсионной формулы для расчета солидарной части трудовой пенсии с учетом стимулирования более позднего выхода на пенсию : материалы НИР / ФГБОУ ВПО «Рос. акад. народ. хоз-ва и гос. службы при Президенте РФ» ; Ю. М. Горлин [и др.]. - М., 2014. - $99 \mathrm{c}$.

11. Реформа пенсионной системы: международный опыт и рекомендации для России / под ред. П. В. Крючковой, А. В. Табаха. - М. : СПРОС : ИИФ КонфОП, 2003. - 71 с.

12. Соловьев А. К. Актуарный прогноз долгосрочного развития пенсионной системы России / А. К. Соловьев // Финансы. - 2012. - № 5. - С. 57-63.

13. Соловьев А. К. Реформа пенсионной системы Российской Федерации: проблемы и решения / А. К. Соловьев // Экономика и управление: проблемы, решения. -2014 . - № 7. C. $26-31$.

14. Соловьев А. К. Уровень пенсионного обеспечения в современной России / А. К. Соловьев, Н. В. Мележик // Народонаселение. - 2014. — № 3. - С. 12-25.

\section{Baikal Research Journal}

электронный научный журнал Байкальского государственного университета 
15. Федорова Е. А. Управление пенсионными накоплениями негосударственными пенсионными фондами / Е. А. Федорова, Ю. А. Разин // Финансы и кредит. — 2015. — № 26. C. $2-10$.

16. Эффективность управления пенсионными накоплениями: теоретические подходы и эмпирический анализ / А. Абрамов [и др.] // Вопросы экономики. - 2015. — № 7. — С. $26-44$.

17. Соловьев А. К. Пенсионные системы в контексте страховых принципов / А. К. Соловьев // Журнал Новой экономической ассоциации. - 2012. - № 3. - C. 141-165.

18. Holzmann R. Global Pension Systems and Their Reform: Worldwide Drivers, Trends, and Challenges [Electronic resource] / R. Holzmann. - The World Bank, 2012. - (Series: Social Protection \& Labor. Discussion Papers. № 1213). - Mode of access : http://siteresources. worldbank.org/SOCIALPROTECTION/Resources/SP-Discussion-papers/Pensions$\mathrm{DP} / 1213 . p d f$.

19. Агеева Е. В. Механизмы адаптации пенсионных систем к процессу старения населения / Е. В. Агеева // Актуальные проблемы формирования государственных доходов в России : сб. науч. тр. / под ред. Д. Ю. Федотова. - Иркутск : Изд-во БГУЭП, 2012. — С. 21-27.

\section{References}

1. Borisenko N. Yu. Building the national system of pension provision: theory and practice. Finansy $i$ kredit = Finance and Credit, 2007, no. 17, pp. 54-65. (In Russian).

2. Dmitriev M. E. Financial state and prospect of reforming the pension system in the Russian Federation. In Baskakov V. N., Orlov A. S. (eds). Pensionnaya reforma $v$ Rossii: otsenka spet sialistov [Pension reform in Russia: specialists' assessment]. Moscow, Journal «Pension» Publ., 1999, pp. 71-89. (In Russian).

3. Maleva T. M., Sinyavskaya O. V. Pensionnaya reforma $v$ Rossii: istoriya, rezul'taty, perspektivy [Pension reform in Russia: history. results, prospects]. Moscow, Pomatur Publ., 2005. 76 p.

4. Ordin O. V. Modelirovanie protsessov perekhoda $k$ nakopitel'noi pensionnoi sisteme. Kand. Diss. [Modelling processes of transition to financial defined contributions. Cand. Diss]. Moscow, 2002. $134 \mathrm{p}$.

5. Roik V. D. Osnovy sotsialnogo strakhovaniya: organizatsiya, ekonomika i pravo [Basics of social insurance: organization, economy and law]. Moscow, Russian Presidential Academy of National Economy and Public Administration Publ., 2007. 456 p.

6. Fedotov D. Yu. The main stages in the evolution of the pension system in Russia. Is toriko-ekonomicheskie issledovaniya = Journal of Economic History \& History of Economics, 2013, vol. 14, no. 3, pp. 70-97. (In Russian).

7. Kotlikoff L. J., Burns S. The coming generation storm: what you need to know about America's economic future. London, The MIT Press, 2004. $306 \mathrm{p}$.

8. Vovchenko N. G., Efremenko I. N. Development directions for pension provision system in terms of structural rebuilding of Russia's financial system. Finansovye issledovaniya = Finan cial Research, 2009, no. 24, pp. 36-42. (In Russian).

9. Gontmakher E. Sh. Ways of improving Russia's pension system. Uroven zhizni naseleniya regionov Rossii $=$ Living Standards in The Regions of Russia, 2008, no. 8, pp. 29-36. (In Russian).

10. Gorlin Yu. M. et al. Razrabotka pensionnoi formuly dlya rascheta solidarnoi chasti trudovoi pensii s uchetom stimulirovaniya bolee pozdnego vykhoda na pensiyu. [Developing pension formula for calculating the joint part of labor pension in view of encouraging delayed retirement]. Moscow, Russian Presidential Academy of National Economy and Public Administration Publ., 2014. 99 p.

11. Kryuchkova P. V., Tabakh A. V. (eds). Reforma pensionnoi sistemy: mezhdunarodnyi opyt i rekomendatsii dlya Rossii [Pension system reform: international experience and recommendations for Russia]. Moscow, SPROS, IIF KonfOP Publ., 2003. 71 p.

12. Solovyev A. K. Actuary forecasting of long-term development of Russia's pension system. Finansy = Finance, 2012, no. 5, pp. 57-63. (In Russian).

13. Solovyev A. K. Reform of Russia's pension system: problems and solutions. Ekonomika i upravlenie: problemy, resheniya = Economics and Management: Problems and Solutions, 2014, no. 7, pp. 26-31. (In Russian).

14. Solovyev A. K., Melezhik N. V. The level of pension provision in modern Russia. Narodonaselenie $=$ Population, 2014, no. 3, pp. 12-25. (In Russian).

\section{Baikal Research Journal}


15. Fedorova E. A., Razin Yu. A. Management of pension savings by non-state pension funds. Finansy $i$ kredit $=$ Finance and Credit, 2015, no. 26, pp. 2-10. (In Russian).

16. Abramov A. et al. Efficiency of managing pension assets: theoretical approaches and empiric analysis. Voprosy ekonomiki = Issues of Economy, 2015, no. 7, pp. 26-44. (In Russian).

17. Solovyev A. K. Pension systems in the context of insurance principles. Zhurnal Novoi ekonomicheskoi assotsiatsii = Journal of New Economic Association, 2012, no. 3, pp. 141-165. (In Russian).

18. Holzmann R. Global pension systems and their reform. Worldwide drivers, trends, and challenges. The World Bank, 2012. (Series: Social Protection \& Labor. Discussion Papers. № 1213). Available at: http://siteresources. worldbank.org/SOCIALPROTECTION/Resources/ SP-Discussion-papers/ Pensions-DP/1213.pdf.

19. Ageyeva E. V. Mechanisms of adapting pension schemes to process of ageing of population. In Fedotov D. Yu. (ed.). Aktual'nye problemy formirovaniya gosudarstvennykh dokhodov $v$ Rossii [Urgent problems of government revenue formation in Russia]. Irkutsk, Baikal State University of Economics and Law Publ., 2012, pp. 21-27. (In Russian).

\section{Информация об авторе}

Будько Сергей Александрович - аспирант, кафедра налогов и таможенного дела, Байкальский государственный университет, 664003, г. Иркутск, ул. Ленина, 11, e-mail: budkosa@mail.ru.

\section{Author}

Sergei A. Budko - PhD Student, Chair of Taxes and Customs Affairs, Baikal State University, 11 Lenin St., 664003, Irkutsk, Russian Federation; e-mail: budkosa@mail.ru.

\section{Библиографическое о писание статьи}

Будько С. А. Формальные условия сбалансированности распределительной пенсионной системы / С. А. Будько / / Baikal Research Journal. — 2016. — T. 7, № 2. — DOI : 10.17150/2411$\underline{6262.2016 .7(2) .5}$.

\section{Reference to article}

Budko S. A. Formal conditions for equation of the unfunded pension scheme. Baikal Research Journal, 2016, vol. 7, no. 2. DOI: 10.17150/2411-6262.2016.7(2).5. (In Russian).

\section{Baikal Research Journal}

